\title{
Laser Metal Deposition of Ti6A14V-A Brief Review
}

\author{
Chongliang Zhong ${ }^{1, *}$, Jianing Liu ${ }^{1}$, Tong Zhao ${ }^{1}$, Thomas Schopphoven ${ }^{1}$, Jinbao Fu ${ }^{2}$, \\ Andres Gasser ${ }^{1}$ and Johannes Henrich Schleifenbaum ${ }^{1,3}$ \\ 1 Fraunhofer ILT-Institute for Laser Technology, 52074 Aachen, Germany; \\ jennyliu.aachen@googlemail.com (J.L.); tong.zhao@ilt.fraunhofer.de (T.Z.); \\ thomas.schopphoven@ilt.fraunhofer.de (T.S.); andres.gasser@ilt.fraunhofer.de (A.G.) \\ 2 Changchun Institute of Optics, Fine Mechanics and Physics, Chinese Academy of Sciences, Changchun \\ 130033, China; fujinbao@ciomp.ac.cn \\ 3 RWTH Aachen University DAP_Digital Additive Production, 52074 Aachen, Germany; \\ johannes.henrich.schleifenbaum@ilt.fraunhofer.de \\ * Correspondence: chongliang.zhong@ilt.fraunhofer.de; Tel.: +49-241-8906-8053
}

Received: 29 November 2019; Accepted: 25 December 2019; Published: 21 January 2020

\begin{abstract}
Laser metal deposition (LMD) is one of the most important laser additive manufacturing processes. It can be used to produce functional coatings, to repair damaged parts and to manufacture metal components. Ti6Al4V is one of the most commonly used titanium alloys, since it features a good balance of the mechanical properties of strength and ductility. The LMD of Ti6Al4V is attracting more and more attention from both science and engineering. The interest in processing Ti6Al4V with LMD in industry, especially in aerospace and medical branches, has been increasing in the last few years. In this paper, the state of the art for LMD of Ti6Al4V is reviewed. In the first part, the basics for Ti6Al4V, including, for example, the development history, the material properties, the applications, the crystal structure, the heat treatment and the mechanical properties, are introduced. In the second part, the main emphasis is on state of the art for LMD of Ti6Al4V. Initially, the process parameters of the current state of the art in the last years and their effects are summarized. After that, the typical microstructure after LMD is discussed. Then, the conducted heat treatment methods and the achievable mechanical properties are presented. In the end, some of the existing, current challenges are mentioned, and the possible research directions for the future are proposed.
\end{abstract}

Keywords: laser metal deposition; Ti6Al4V; microstructure; heat treatment; mechanical properties

\section{Introduction}

Laser metal deposition (LMD) is an additive manufacturing process, by which a laser beam is used as the energy source to form a melt pool on the surface of a metallic substrate into which metal powder is injected by a gas stream and melted. The main applications of LMD are repairing damaged parts, cladding functional layers and the additive manufacturing of metal components. It is a free-form fabrication method that allows to manufacture metal components directly from three-dimensional CAD files by adding materials layer by layer. The metal powder is in most cases co-axially fed by an insert carrier gas into a melt pool [1]. In order to avoid oxidation, the melt pool must be protected from the atmosphere. Thus, LMD is normally conducted in a process chamber filled with inert gas, or under local shielding by an inert gas stream [2].

LMD has a variety of advantages over other deposition processes; for example, the lower heat input and the related smaller heat affected zone, by which the deformation can be significantly reduced and the heat influence on the surface of the substrate can be minimized. Another advantage is the higher cooling rate, which leads to a finer microstructure, and this is generally positive for the material performance [3]. 
Titanium alloys have found their applications in various areas, including automobile, aerospace and petrochemical industries, and offshore equipment and medical implements, because of their excellent properties, such as high strength-to-weight ratio, high corrosion resistance and bio compatibility [4]. Ti6Al4V is one of the most commonly used titanium alloys thanks to its good balance of material properties [5]. Ti6Al4V has the same strength as steel with a density of less than approximately $40 \%$ of steel's, offering weight saving, replacement costs and life cycle costs benefits; meanwhile, a stable, protective and strong adherent oxide film provides an excellent corrosion resistance to Ti6Al4V, which can, thereby, serve in seawater 15 times longer than steel [6,7]. As a result, there has been a significant increase in the usage of Ti6Al4V in the industries in the past two decades [8].

Therefore, LMD of Ti6Al4V is attracting more and more attention from both science and engineering. An increasing number of applications for laser metal deposited Ti6Al4V are in industry, especially in aerospace and medical branches. In this work, the state of the art for LMD of Ti6Al4V will be based on the reviewing of the scientific work conducted in the last few years. In this regard, the process parameters, macrostructure and microstructure, heat treatment methods and the achievable mechanical properties, are the focal points.

\section{Ti6Al4V}

\subsection{General Information}

Titanium is the fourth-most abundant structural metal in the earth's crust [9]. However, titanium rarely exists in a concentrated form. As a result, titanium has a relatively short production history. The element titanium was discovered in England by the Reverend William Gregor in 1790, and was first purified in the United State by M. A. Hunter at the General Electric Company in 1906 [10,11]. In the 1950s, numbers of companies managed to meet the challenge to produce titanium. The value of aluminum and vanadium as alloy additions was established in the "Workhorse alloy" Ti6Al4V, which was patented by Crucible Steel in 1954 [12]. Since then, Ti6Al4V has been widely used for lightweight parts in variety of industrial products [13].

The chemical composition of Ti6Al4V is shown in Table 1.

Table 1. Chemical composition of Ti6Al4V.

\begin{tabular}{ccccccccccc}
\hline Chem. Element wt.\% & $\mathbf{A l}$ & $\mathbf{V}$ & $\mathbf{F e}$ & $\mathbf{O}$ & $\mathbf{N}$ & $\mathbf{C}$ & $\mathbf{H}$ & $\mathbf{T i}$ & Others (Each) & Others (Total) \\
\hline Min. & 5.50 & 3.50 & 0 & 0 & 0 & 0 & 0 & balance & 0 & 0 \\
Max. & 6.75 & 4.50 & 0.40 & 0.20 & 0.05 & 0.08 & 0.015 & balance & 0.10 & 0.40 \\
\hline
\end{tabular}

Ti6Al4V is designed for a good balance of strength, ductility, fatigue and fracture properties. Ti6Al4V has been used as an important structural material in advanced aircraft since the 1960s [14]. Nippon Steel and the Sumitomo Metal Corporation acquired qualifications in 1985 from Rolls-Royce and started commercial production of titanium alloys for aircraft engines. Furthermore, the company concluded a long-term agreement with Airbus in 2002 and has been consistently supplying titanium for Airbus's airframes [5].

In aerospace, Ti6Al4V is mainly used for airframe and engine parts. An expansion of the demand on the market is expected due to the requirement of low fuel consumption by aircraft. In airframes, it is used for structural materials, such as bolts and seat rails; in engines, due to the relatively low allowable temperature of about $300{ }^{\circ} \mathrm{C}$ of the material, it is used for fan blades, fan cases and engine suspension, where the working temperatures are lower than $300^{\circ} \mathrm{C}$ [5]. Additive manufactured parts, such as cabin brackets and bleed pipes, are already being applied in test aircraft of new models, such as Airbus A320neo and A350 XWB parts. The current knowledge can already allow the parts produced by additive manufacturing to replace those which were produced by conventional process [15]. 


\subsection{Crystal Structure}

Titanium is known to exist in two different crystal structures: a close packed hexagonal $\alpha$ phase and a body-centered-cubic $\beta$ phase [16].

Alloying elements in titanium can be categorized into $\alpha$-stabilizers, $\beta$-stabilizers or neutral additions, depending on which phase the elements tend to stabilize, or whether they effectively increase or decrease the solid-state $\alpha-\beta$ transus temperature of titanium [14]. $\alpha$-stabilizers, including the substitutional element (aluminum) and the interstitial elements (oxygen, nitrogen and carbon), strongly increase the threshold temperature at which the $\alpha$ phase is stable, even if the solute content increases. $\beta$-stabilizers, including isomorphous elements (vanadium, molybdenum, niobium and tantalum) and eutectoid elements (ferrous, manganese, chromium and nickel), stabilize the $\beta$ phase at lower temperatures. In addition, some neutral elements (zirconium, hafnium and tin) have no significant influence on the $\beta$ transus temperature $[14,17]$.

$\alpha+\beta$ alloys, such as Ti6Al4V, have a high-strength and formability and contain 4-6 wt.\% $\beta$-stabilizers, which allow substantial amounts of $\beta$ phases to be retained from the $\alpha+\beta$ phase fields after quenching. Al reduces the density of the alloy and stabilizes the $\alpha$ phase, while vanadium provides a greater amount of the more ductile $\beta$ phase for hot-working [18].

As an $\alpha+\beta$ alloy, Ti6Al4V contains both an $\alpha$-stabilizer (aluminum) and a $\beta$-stabilizer (vanadium), and thus has a moderate strength and weldability. Ti6Al4V by far is the best adopted titanium alloy for additive manufacturing. The lowest temperature at which a $100 \% \beta$ phase can exist is called the beta transus. The addition of alloying elements to Ti leads to an increase of the $\beta$ transus temperature from $882{ }^{\circ} \mathrm{C}$ of pure titanium to $980{ }^{\circ} \mathrm{C}$, and approximately $9 \pm 2 \mathrm{wt} . \%$ of the $\beta$ phase is retained at room temperature. The majority of the diffusion transformation occurs within the temperature range between 850 and $950{ }^{\circ} \mathrm{C}$ at a transformation cooling rate between 5 and $50{ }^{\circ} \mathrm{C} / \mathrm{s}$ [14]

\subsection{Heat Treatment and Mechanical Properties}

Heat treatments are performed on Ti6Al4V in order to modify its microstructure, to increase strength or ductility, to reduce the residual stress and/or to optimize the fatigue strength or high-temperature strength [19].

The first commonly used heat treatment is the solution treatment followed by quenching and aging, through which the strength of Ti6Al4V is increased by turning $\beta$ phases into $\alpha$ martensite phases [13]. Another typical heat treatment is annealing to get equiaxed microstructure, which is isotropic.

The specifications (ASTM F1108 for casted and ASTM F1472 for annealed material) for the mechanical properties for Ti6Al4V are presented in Table 2. ASTM is short for American Society for Testing and Materials.

Table 2. Specifications for the mechanical properties for Ti6Al4V.

\begin{tabular}{ccc}
\hline & Cast Material & Annealed Material \\
\hline & ASTM F1108 & ASTM F1472 \\
Yield Strength $\left(R_{p 0.2}\right)$ & $758 \mathrm{MPa}$ & $860 \mathrm{MPa}$ \\
Ultimate Tensile Strength $\left(R_{m}\right)$ & $860 \mathrm{MPa}$ & $930 \mathrm{MPa}$ \\
Elongation at break $(\%)$ & $>8$ & $>10$ \\
Reduction of Area $(\%)$ & $>14$ & $>25$ \\
\hline
\end{tabular}

\section{LMD of Ti6Al4V}

\subsection{Process Parameters}

Literature for the research work regarding LMD of Ti6Al4V in the last five years has been reviewed. The process parameters (powder feeding rate, laser power, scanning speed and laser beam 
diameter), the dimensions of the samples built and the manufacturing processes of the powders (GA: gas atomization; PREP: plasma rotating electrode process) have been summarized in Table 3.

Table 3. Process windows of laser metal deposition (LMD) of Ti6Al4V.

\begin{tabular}{|c|c|c|c|c|c|c|}
\hline & $\begin{array}{c}\text { Powder } \\
\text { Feeding Rate } \\
m_{P}(\mathrm{~kg} / \mathrm{h})\end{array}$ & $\begin{array}{c}\text { Laser } \\
\text { Power } \\
P_{L}(W)\end{array}$ & $\begin{array}{c}\text { Scanning } \\
\text { Speed } \\
\text { v (mm/min) }\end{array}$ & $\begin{array}{c}\text { Laser Spot } \\
\text { Diameter } \\
\text { d (mm) }\end{array}$ & $\begin{array}{l}\text { Geometry } \\
\text { of Samples } \\
(\mathrm{mm})\end{array}$ & $\begin{array}{c}\text { Powder Type/ } \\
\text { Particle Size } \\
d_{p}(\mu \mathrm{m})\end{array}$ \\
\hline Kelbassa [20] & $0.036-0.096$ & $250-500$ & 500 & 1.3 & $50 \times 10 \times 10$ & GA/45-71 \\
\hline Mahamood & $0.12-0.24$ & $1500-3000$ & 3000 & 3 & 6 layers & GA/150-200 \\
\hline Erinosho [25] & - & $600-1800$ & 300 & 4 & Single tracks & $-/ 150-200$ \\
\hline Heigel [26] & 0.18 & $410-415$ & 510 & 3 & $38.1 \times 12.7 \times 3$ & $-/ 44-149$ \\
\hline Yan [27] & - & 3500 & $120-2400$ & $0.5-4.1$ & $250 \times 250 \times 400$ & $-/ 10-200$ \\
\hline Li [28] & $0.9-1.8$ & 7000 & $600-900$ & 6 & $80 \times 53 \times 60$ & $-/ 40-100$ \\
\hline Qiu [29] & $0.36-0.96$ & $800-1500$ & $600-1000$ & $0.2-6$ & Thin walls & $-/ 75-105$ \\
\hline Carroll [30] & 0.48 & 2000 & 636 & 4 & Thin walls & PREP/89 \\
\hline Sterling [31] & 0.576 & 350 & 1015.8 & 1.1 & 5 layers & PREP / 45-150 \\
\hline Paydas [32] & $\begin{array}{c}0.1 \\
0.019\end{array}$ & $\begin{array}{c}2000 \\
300\end{array}$ & $\begin{array}{l}400 \\
600\end{array}$ & $\begin{array}{c}1.4 \\
0.036\end{array}$ & $39 \times 20 \times 5$ & PREP/45-78 \\
\hline Wang [33] & $0.36-3.54$ & 6000 & 1000 & 6 & Thin walls & PREP/80-250 \\
\hline Nassar [34] & 0.18 & 500 & 634.8 & 1.24 & $24 \times 38 \times 9$ & $-/ 126.8$ \\
\hline Raju [35] & 0.24 & 1500 & $500-700$ & 2 & $20 \times 4.5 \times 2$ & GA/45-100 \\
\hline Ravi [36] & - & $480-1800$ & $700-1000$ & - & $22 \times 22 \times 16$ & PREP / 45-150 \\
\hline Yan [37] & - & $550-750$ & $200-400$ & 3 & $12.7 \times 6.4 \times 50.8$ & $-/ 106-175$ \\
\hline Wolff [38] & 0.432 & $710-940$ & 600 & 1.83 & $40 \times 40 \times 40$ & $-/ 45-150$ \\
\hline Zhai [39] & $0.06 / 0.12$ & $330 / 780$ & $600 / 800$ & - & $102 \times 51 \times 8$ & $\begin{array}{c}\text { GA/- } \\
64 \times 13 \times 43 \\
51 \times 13 \times 38\end{array}$ \\
\hline Sridharan [40] & 0.126 & 400 & 635 & - & 4 layers & PREP / 44-120 \\
\hline Reichardt [41] & $0.042-0.18$ & 600 & 762 & - & Thin walls & $-/ 44-177$ \\
\hline Keist [42] & 0.72 & 2000 & 600 & 4 & Thin walls & PREP/58-156 \\
\hline Marshall [43] & 0.468 & 350 & 1014 & 2.9 & $6.6 \times 6.6 \times 78.2$ & PREP/45-150 \\
\hline Ogunlana [44] & 0.4 & $800-2400$ & 1000 & 4 & Single tracks & $-/ 45-90$ \\
\hline
\end{tabular}

In I. Kelbassa's doctoral thesis, the experiments of LMD with Ti6Al4V were carried out in the open atmosphere in Fraunhofer ILT in 2006 [20]. To the authors' knowledge, all other experiments were carried out in process chambers. Compared with deposition in the process chamber, LMD in the open atmosphere is characterized by many advantages: the dimensions of the part deposited are not limited by the chamber size; the time to establish the shielding gas atmosphere can be saved; the flexibility of the process can be improved. However, there are also advantages of LMD in process chambers: the melt pool is protected from oxidation and the users are not exposed to the metal powders so that the metal powders are less likely to be inhaled.

GA and PREP are two main methods for the production of metallic powders for LMD. GA is the most common method of powder production, during which a molten feedstock is atomized by inert gas jets into fine metal droplets which cool down and solidified during the falling. Another process for the titanium powder production is the PREP in which plasma arc is utilized for a centrifugal atomization process [45]. Laser additive manufactured specimens formed by gas-atomized powders have a higher porosity, a higher surface roughness and a larger dilution zone, than those in specimens formed by PREP powder [46]. Nevertheless, the prise of the PREP powder is higher.

According to Table 3, the powder feeding rate lies in the range of $0.06-3.54 \mathrm{~kg} / \mathrm{h}$. With the assumption of a powder deposition efficiency of around 70\%, the deposition rate for LMD of Ti6Al4V is normally lower than $0.5 \mathrm{~kg} / \mathrm{h}$. The laser's power for the majority research is between 300 and $3000 \mathrm{~W}$, and the scanning speed is $300-1000 \mathrm{~mm} / \mathrm{min}$. A laser beam with a diameter of $1-4 \mathrm{~mm}$ is typically used. 
Many researches are focused on effects of main process parameters on surface roughness, microstructures, deposition efficiency, corrosion resistance and wear resistance. The effects of these parameters can be summarized as follows:

- Powder flow rate: an increase in powder flow rate can lead to an increase in microhardness and surface roughness [23].

- Laser power: A lower surface roughness can be achieved by using a higher laser power [24]; the porosity is inversely proportional to the laser power [25,44]. However, with increased laser power, the corrosion rate and the microhardness are reduced [21,47]. Laser power has significant effects on deposition efficiency and wear resistance as well; and strong interactions with scanning speed and the powder flow rate [4,22]. Moreover, laser power shows a significant influence on the grain size and the phase structure-increased laser power leading generally to coarser grains and microstructures $[36,48]$.

- Scanning speed: an increase in scanning speed causes generally an increase in solidification rate, microhardness and surface roughness [21,23]. Mahamood has, in his work, observed that the wear resistance performance of samples rises first and then decreases with increasing scanning speed, with the turning point at $0.065 \mathrm{~m} / \mathrm{s}[23,49]$.

\subsection{Macrostructure and Microstructure}

In $\alpha+\beta$ alloy, the room-temperature equilibrium microstructure consists mainly of $\alpha$ phases (hexagonal close packed) with some retained $\beta$ phases (body center cubic). The $\beta$ phases are fully or partly transformed into $\alpha$ with a martensitic type, which has two different forms; namely, the hexagonal $\alpha\left(\alpha^{\prime}\right)$ and the orthorhombic $\alpha\left(\alpha^{\prime \prime}\right)$ [50]. The phase transformation strongly depends on the temperature history and the cooling rate during deposition [51]. $\alpha^{\prime}$ martensite forms within a specific cooling rate range between 20 and $410^{\circ} \mathrm{C} / \mathrm{s}$ [52]. The formation of $\alpha$ prime $\left(\alpha^{\prime}\right)$ martensite phase is beneficially produced by the rapid cooling through diffusionless transformation, while $\alpha+\beta$ transformation is a diffusional process [53]. The $\alpha$ platelets are thicker and shorter when the cooling rate decreases, and even transformed into a global type with very low cooling rates. The four typical microstructures in $\alpha+\beta$ alloys are shown in Figure 1 .
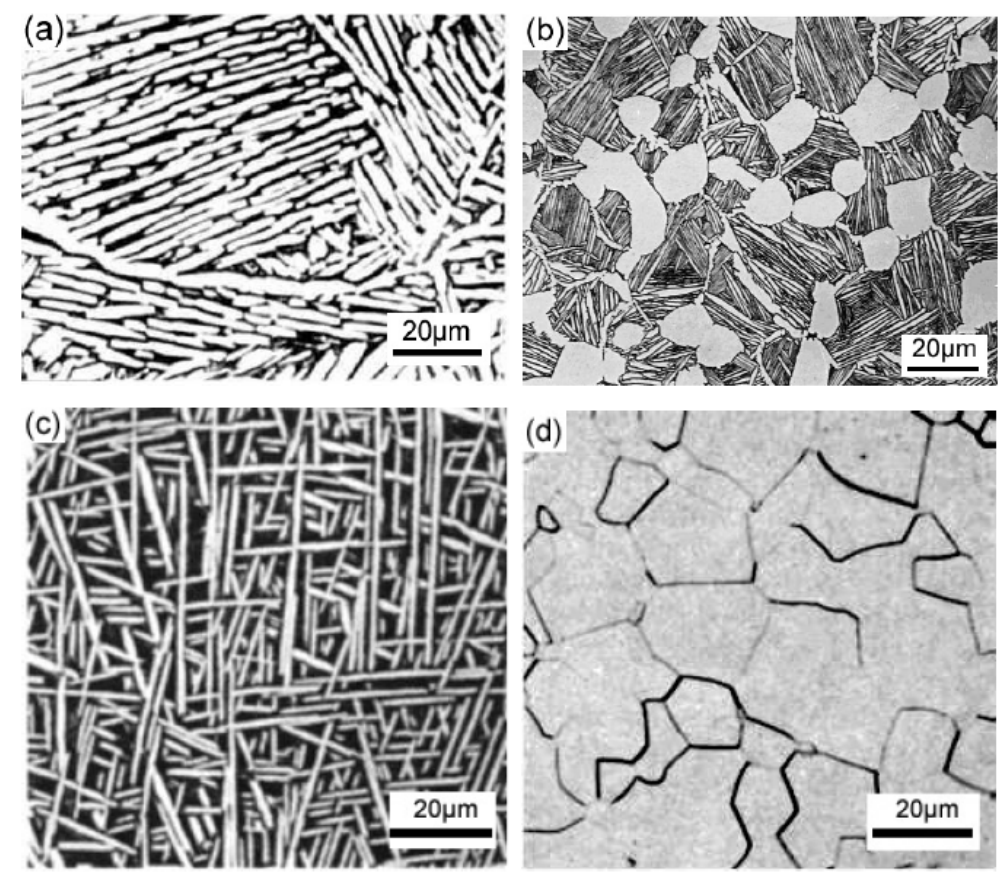

Figure 1. Typical microstructures of $\alpha+\beta$ titanium alloys: (a) Widmanstätten; (b) duplex microstructure; (c) basket-weave microstructure; (d) equiaxed structure (adapted from [54]). 
There are numerous choices of etchants for revealing Ti6Al4V's microstructures: Kroll's reagent, oxalic reagent, ammonium bifluoride and so on [17]. Among those, Kroll's reagent is most widely used, as it can easily meet almost all the demands in the laboratory. Chemical etching by Kroll's reagent for Ti6Al4V is listed in ASTM E407 as etchant number 192. Kroll's Reagent is a solution mixture of $75 \mathrm{~mL}$ $\mathrm{H}_{2} \mathrm{O}, 22 \mathrm{~mL} \mathrm{HNO}_{3}$ and $3 \mathrm{~mL}$ HF. The metallurgical samples are dipped into the solution and stirred gently for 20-30 s. These typical microstructures can be summarized as follows:

- Widmanstätten: Primary $\beta$ grains are coarse and complete. Continuous $\alpha$ particles grow on the grain boundary. The colonies of $\alpha$ lamellae are thick and parallel. After slow cooling (furnace cooling) from $\beta$ phase zone, Widmanstätten structure with a low ductility and a high fatigue performance could be seen.

- Duplex microstructure: No more than $50 \%$ of the discontinuous equiaxed $\alpha$ particles distribute in transformed $\beta$ matrix. When alloy is heated or deformed in the upper part of $\alpha+\beta$ phase zone, a duplex microstructure with a comprehensive performance of mechanical properties can be achieved.

- Basket-weave microstructure: primary $\beta$ grain boundaries are destroyed and the $\alpha$ lamellae become shorter in multiple orientations. When a large deformation is performed near $\beta$ transus temperature, basket-weave structure with enhanced ductility is formed.

- Equiaxed structure: More than $50 \%$ of the primary $\alpha$ grains and a certain amount of the transformed $\beta$ grains display an irregular polygon shape. With a higher deformation rate, higher temperature, longer time of temperature holding, the equiaxial level is lifted, with a result of an excellent overall performance.

An increase in cooling rate leads to a refinement of the microstructure-both $\alpha$ colony size and $\alpha$-lamellae thickness reduce. New colonies tend to nucleate not only on $\beta$-phase boundaries but also on boundaries of other colonies and grow perpendicularly to the existing lamellae [55].

In the case of fabrication of large structures by LMD of titanium alloys, the heat is found mainly dissipated away through the conduction along Z-direction by conduction through the previously deposited material during the deposition process. The typical macrostructure and microstructure of laser metal deposited Ti6Al4V are illustrated in Figure 2.

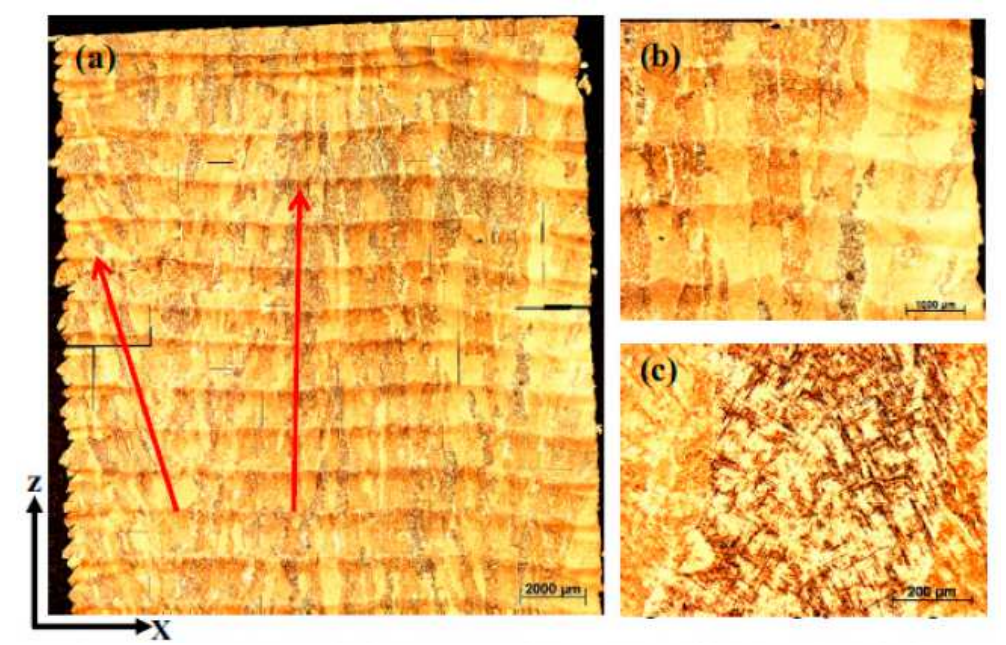

Figure 2. Typical macrostructure and microstructure of as-deposited sample of Ti6Al4V: (a) grain structure in as-deposited sample; (b) x-sectional micrograph; (c) z-sectional micrograph (adapted from [56]).

As shown in Figure 2, primary $\beta$ grains decorated with fine $\alpha$ phases grow approximately in the build direction and through the deposition layers [57,58]. The size, shape and distribution of parent $\beta$ grains definitely affects the morphology of $\alpha / \alpha^{\prime}$ phases [33]. The growth direction of the majority of 
the $\alpha$ plates shows an inclination towards the build direction (as shown with arrow with red color). Macrostructure is columnar with the longitudinal axis parallel to the build direction in deposited specimens of Ti6Al4V. The grain size tends to decrease with an increase of the cooling rate. It has been observed that fine-grained microstructures in which fine equiaxed particles distribute are both inside every grain and along the grain boundaries [56].

\subsection{Heat Treatment and Mechanical Properties}

The heat treatment that includes solution treatment and aging is a prefered method to get favorable properties, balanced strength and ductility. The temperature for solution treatment is most significant for getting the expected microstructures and properties, and is, therefore, set $40-100{ }^{\circ} \mathrm{C}$ lower than $\beta$ transus temperature, in order to get a certain proportion between primary $\alpha$ and primary $\beta$ phases through a following rapid cooling (air cooling) [54]. Oversaturated, metastable $\beta_{m}$ phases can also be generated, which enable the growth of primary $\alpha$ phases and the participation of secondary $\alpha$ phases during aging.

Stress-relief annealing is another typical treatment for enhancing the ductility. The stress-relief annealing weakens the $\beta-\alpha$ phase transformation and facilitates, thereby, the precipitation and growth of $\alpha$ phases, leaving the type of the microstructure unchanged. Primary $\alpha$ become coarse after annealing [7].

In the heat treatment, the cooling rate is another important factor which has an impact on the microstructure and the mechanical properties besides the temperature. The relationship between the cooling rate and the microstructure is shown in Figure 3.

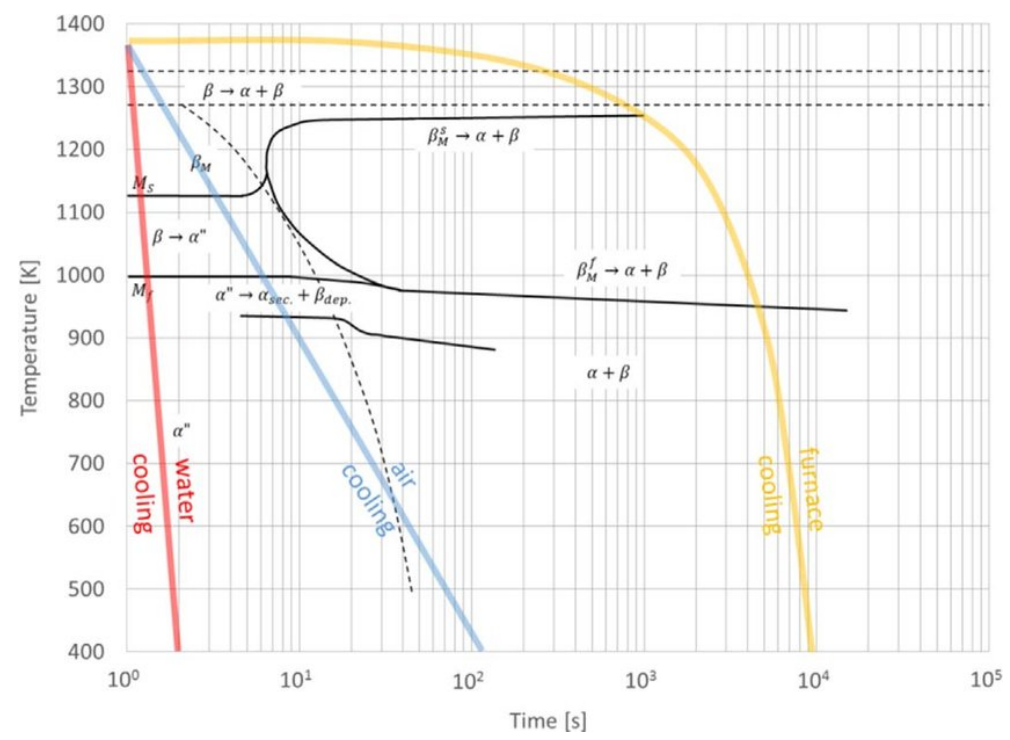

Figure 3. Continuous Cooling Transformation (CCT) diagram for Ti6Al4V. The three colorful curves represent the thermal profiles of water, air and furnace cooling(adapted from [59]).

The cooling method used after the higher-temperature annealing can affect tensile properties [19]. The thermal profile of heat treatment influences the final microstructure [60]. As shown in Figure 3, after the fast cooling, such as water cooling with a rate around $1000^{\circ} \mathrm{C} / \mathrm{s}$, the microstructure can be fully transformed into $\alpha^{\prime}$ martensite. The air cooling rate is as estimated at around $20^{\circ} \mathrm{C} / \mathrm{s}$ from $1100{ }^{\circ} \mathrm{C}$ to $500{ }^{\circ} \mathrm{C}$ [59]. In the case of cooling with an intermediate rate of about $3.5^{\circ} \mathrm{C} / \mathrm{s}$, the martensitic transformation is accompanied by diffusional transformation, and hence, the volume fraction of martensitic phases decreases to the benefit of the stabilization of the $\alpha$ and $\beta$ phases [55]. The cooling rate of a furnace cooling condition is around $2{ }^{\circ} \mathrm{C} / \mathrm{s}$ [61]. With an extremely slow cooling rate, a fully lamellar or a duplex microstructure could even be achieved [62]. 
Based on the literature review, the mechanical properties (yield strength, tensile strength and elongation at break) of Ti6Al4V fabricated by LMD with and without heat treatment have been summarized in Table 4.

Table 4. Mechanical properties of specimens of Ti6Al4V fabricated by LMD.

\begin{tabular}{|c|c|c|c|c|c|c|c|}
\hline & $\begin{array}{c}\text { Powder } \\
\text { Feeding Rate } \\
m_{P} \\
(\mathrm{~kg} / \mathrm{h})\end{array}$ & $\begin{array}{c}\text { Laser } \\
\text { Power } \\
P_{L} \\
(W)\end{array}$ & $\begin{array}{c}\text { Scanning } \\
\text { Speed } \\
\mathbf{v} \\
(\mathrm{mm} / \mathrm{min})\end{array}$ & $\begin{array}{c}\text { Tensile } \\
\text { Axis } \\
\text { Orientation }\end{array}$ & $\begin{array}{c}\text { Yield } \\
\text { Strength } \\
R_{p} 0.2 \\
(\mathrm{MPa})\end{array}$ & $\begin{array}{c}\text { Tensile } \\
\text { Strength } \\
R_{m} \\
(\mathrm{MPa})\end{array}$ & $\begin{array}{c}\text { Elongation } \\
A_{5} \\
(\%)\end{array}$ \\
\hline \multirow[t]{6}{*}{ Kelbassa [20] } & \multirow[t]{2}{*}{0.036} & \multirow[t]{2}{*}{450} & \multirow[t]{2}{*}{500} & vertical & 984.37 & 1094.2 & 4.2 \\
\hline & & & & horizontal & 1040.8 & 1151.7 & 2.2 \\
\hline & \multirow{2}{*}{\multicolumn{3}{|c|}{$\begin{array}{l}955^{\circ} \mathrm{C}, 1 \mathrm{~h} \text {, helium quenching } \\
+700^{\circ} \mathrm{C}, 2 \mathrm{~h} \text {, argon cooling }\end{array}$}} & vertical & 922.2 & 1038.3 & 11.49 \\
\hline & & & & horizontal & 933.9 & 1035.6 & 7.11 \\
\hline & \multirow{2}{*}{\multicolumn{3}{|c|}{$640^{\circ} \mathrm{C}, 1 \mathrm{~h}$, vacuum oven cooling }} & vertical & 1008.9 & 1112 & 9.5 \\
\hline & & & & horizontal & 1050.5 & 1147.3 & 7.07 \\
\hline \multirow[t]{3}{*}{ Qiu [29] } & \multirow{2}{*}{$0.39-0.45$} & \multirow{2}{*}{$1100-1200$} & \multirow{2}{*}{$750-850$} & vertical & $950 \pm 2$ & $1025 \pm 2$ & $5 \pm 1$ \\
\hline & & & & horizontal & $950 \pm 2$ & $1025 \pm 10$ & $12 \pm 1$ \\
\hline & \multicolumn{3}{|c|}{$920^{\circ} \mathrm{C}, 100 \mathrm{MPa}, 4 \mathrm{~h}$, furnace cooling } & - & $850 \pm 2$ & $920 \pm 1$ & $17 \pm 2$ \\
\hline \multirow[t]{3}{*}{ Carroll [30] } & \multirow[t]{3}{*}{0.48} & \multirow[t]{3}{*}{2000} & \multirow[t]{3}{*}{636} & vertical (top) & $945 \pm 13$ & $1041 \pm 12$ & $14.5 \pm 1.2$ \\
\hline & & & & vertical (bottom) & $970 \pm 17$ & $1087 \pm 8$ & $13.6 \pm 0.5$ \\
\hline & & & & horizontal & $960 \pm 26$ & $1063 \pm 20$ & $10.9 \pm 1.4$ \\
\hline \multirow[t]{3}{*}{ Sterling [31] } & 0.576 & 350 & 1015.8 & horizontal & 908 & 1038 & 3.8 \\
\hline & \multirow{2}{*}{\multicolumn{3}{|c|}{$\begin{array}{l}704^{\circ} \mathrm{C}, 1 \mathrm{~h} \text {, furnace cooling } \\
1050^{\circ} \mathrm{C}, 2 \mathrm{~h} \text {, furnace cooling }\end{array}$}} & & 959 & 1049 & 3.7 \\
\hline & & & & & 957 & 1097 & 3.4 \\
\hline \multirow[t]{4}{*}{ Zhai [39] } & 0.06 & 330 & 600 & horizontal & 1005 & 1103 & 4 \\
\hline & \multicolumn{3}{|c|}{$760 \pm 4^{\circ} \mathrm{C}, 1 \mathrm{~h}$, air cooling } & & 1000 & 1073 & 9 \\
\hline & 0.12 & 780 & 800 & & 990 & 1042 & 7 \\
\hline & \multicolumn{3}{|c|}{$760 \pm 4^{\circ} \mathrm{C}, 1 \mathrm{~h}$, air cooling } & & 991 & 1044 & 10 \\
\hline \multirow[t]{2}{*}{ Keist [42] } & \multirow[t]{2}{*}{0.72} & \multirow[t]{2}{*}{2000} & \multirow[t]{2}{*}{600} & vertical & $916 \pm 34$ & $1032 \pm 31$ & $19 \pm 4$ \\
\hline & & & & horizontal & $961 \pm 40$ & $1072 \pm 33$ & $17 \pm 4$ \\
\hline
\end{tabular}

As shown in Table 4, the tensile strength and the yield strength are strongly influenced by the parameters and the experimental systems. The strengths and observed elongation in the work of Carroll et al. meet the specification of annealed material, while the results from others are of higher strengths and lower ductilities. Some studies are focused on the anisotropic tensile behavior: the ductility along the build direction is significantly higher than that along the scanning direction. After heat treatment, the elongations can be strongly increased with lightly decreased strengths.

\section{Summary and Outlook}

LMD of Ti6Al4V is becoming a well established process for producing parts with complex structures. The microstructure and mechanical properties have been relatively well studied. Direct after LMD, the material features a columnar grains with $\alpha$ martensite inside. Laser metal deposited Ti6Al4V presents higher strength, but lower ductility. By applying post heat treatment, a strength-ductility balance can be achieved. After appropriate heat treatment, the specifications for the static mechanical properties, such as the ultimate strength, the yield strength and the elongation, can be met.

For further research, the heat treatment methods should be further developed to modify the microstructure, since the previous results show that the laser metal deposited Ti6Al4V presents generally lower ductility, even after the heat treatment documented in the literature.

Additionally, in order to increase the productivity, the deposition rate should be further improved. Currently, the deposition rates for the typical processes are generally smaller than $0.5 \mathrm{~kg} / \mathrm{h}$. In comparison to LMD, other materials such as Inconel 625, can achieve a deposition rate of more than $5 \mathrm{~kg} / \mathrm{h}$; the achievable deposition rate with Ti6Al4V is quite low. For the increase of the deposition rate, the plant and system technologies must be adapted. For example, the powder feeding nozzle for higher powder feeding rate should be developed and laser source with high power should be applied. 
Last but not least, it would be interesting for both research and industry, if the process could be conducted under an open atmosphere. As shown in the state of the art, it is difficult to process Ti6Al4V by local shielding because of the high sensitivity to oxidation of the material. Nevertheless, by adapting the system technology, it should be possible, which has been shown by the work from Kelbassa [20]. If the process can be carried out by local shielding, the complex systems for controlling gas atmosphere are no longer necessary. In addition, the processing time and the resources can be essentially reduced.

Author Contributions: Conceptualization and writing, C.Z. and J.L.; writing-review and editing, C.Z., J.L., T.Z. and J.F.; writing review and editing, T.S.; supervision, A.G. and J.H.S. All authors have read and agreed to the published version of the manuscript.

Funding: This research received no external funding.

Conflicts of Interest: The authors declare no conflict of interest.

\section{References}

1. Kobryn, P.A.; Moore, E.H.; Semiatin, S.L. The effect of laser power and traverse speed on microstructure, porosity, and build height in laser-deposited Ti-6Al-4V. Scr. Mater. 2000, 4, 299-305. [CrossRef]

2. Yu, J.; Rombouts, M.; Maes, G.; Motmans, F. Material Properties of Ti6Al4V Parts Produced by Laser Metal Deposition. Phys. Procedia 2012, 39, 416-424. [CrossRef]

3. Gasser, A.; Backes, G.; Kelbassa, I.; Weisheit, A.; Wissenbach, K. Laser Additive Manufacturing: Laser Metal Deposition (LMD) and Selective Laser Melting (SLM) in Turbo-Engine Applications. Laser Tech. J. 2010, 7, 58-63. [CrossRef]

4. Mahamood, R.M.; Akinlabi, E.T. Effect of Laser Power and Powder Flow Rate on the Wear Resistance Behaviour of Laser Metal Deposited TiC/Ti6Al4V Composites. Mater. Today Proc. 2015, 2, 2679-2686. [CrossRef]

5. Inagaki, I.; Takechi, T.; Shirai, Y.; Ariyasu, N. Application and Features of Titanium for the Aerospace Industry; Nippon Steel \& Sumitomo Metal Technical Report; NIPPON STEEL CORPORATION: Fukuoka, Janpan, 2014; pp. 22-27.

6. Mountford, J.A. Titanium-Properties, Advantages and Applications Solving the Corrosion Problems in Marine Service; NACE International: Houston, TX, USA, 2002.

7. Zhang, S.; Lin, X.; Chen, J.; Huang, W. Heat-treated microstructure and mechanical properties of laser solid forming Ti-6Al-4V alloy. Rare Met. 2009, 28, 537-544. [CrossRef]

8. Rawal, S.; Brantley, J.; Karabudak, N. Additive manufacturing of Ti-6Al-4V alloy components for spacecraft applications. In Proceedings of the 2013 6th International Conference on Recent Advances in Space Technologies (RAST), Istanbul, Turkey, 12-14 June 2013; pp. 5-11.

9. Batalu, D.; Cosmeleata, G.; Aloman, A. Critical analysis of the Ti-Al phase diagrams. UPB Sci. Bull. Ser. B 2006, 68, 77-90.

10. Hadjixenophontos, E. Hydrogen Transport in Thin Films: $\mathrm{Mg}-\mathrm{MgH}_{2}$ and $\mathrm{Ti}-\mathrm{TiH}_{2}$ Systems. Ph.D. Thesis, University of Stuttgart, Stuttgart, Germany, 2018

11. Froes, F.H. Titanium: Physical Metallurgy, Processing, and Applications; ASM International: $\mathrm{Cleveland,} \mathrm{OH}$, USA, 2015.

12. Van Arkel, A.C. History and Extractive Metallurgy. In Titanium-Physical Metallurgy, Processing, and Applications; ASM International: Cleveland, OH, USA, 2015.

13. Morita, T.; Hatsuoka, K.; Iizuka, T.; Kawasaki, K. Strengthening of Ti-6Al-4V Alloy by Short-Time Duplex Heat Treatment. Mater. Trans. 2005, 46, 1681-1686. [CrossRef]

14. Zhao, H. Microstructure Heterogeneity in Additive Manufactured Ti6Al4V. Ph.D. Thesis, The University of Manchester, Manchester, UK, 2017.

15. Mardaras, J.; Emile, P.; Santgerma, A. Airbus approach for F\&DT stress justification of Additive Manufacturing parts. Procedia Struct. Integr. 2017, 7, 109-115.

16. Leyens, C.; Peters, M. Titanium and Titanium Alloys: Fundamentals and Applications; Wiley-VCH: Weinheim, Germany; John Wiley: Chichester, UK, 2003. 
17. Gammon, L.M.; Briggs, R.D.; Packard, J.M.; Batson, K.W.; Boyer, R.; Domby, C.W. Metallography and microstructures of titanium and its alloys. In ASM Handbok; ASM International: Materials Park, OH, USA, 2004; Volume 9, pp. 899-917.

18. Bhadeshia, H.K.D.H. Titanium and Its Alloys. Materials Science and Metallurgy; Lecture Notes; Univerisity of Cambridge: Cambridge, UK, 2013.

19. Donachie, M.J. Titanium: A Technical Guide; ASM International: Cleveland, OH, USA, 2000.

20. Kelbassa, I. Qualifizieren des Laserstrahl-Auftragschweißens von BLISKs aus Nickel-und Titanbasislegierungen. Ph.D. Thesis, RWTH Aachen University, Aachen, Germany, 2006.

21. Mahamood, R.M.; Akinlabi, E.T.; Akinlabi, S. Laser power and Scanning Speed Influence on the Mechanical Property of Laser Metal Deposited Titanium-Alloy. Lasers Manuf. Mater. Process. 2015, 2, 43-55. [CrossRef]

22. Mahamood, R.M.; Akinlabi, E.T. Processing Parameters Optimization for Material Deposition Efficiency in Laser Metal Deposited Titanium Alloy. Lasers Manuf. Mater. Process. 2016, 3, 9-21. [CrossRef]

23. Mahamood, R.M.; Akinlabi, E.T. Scanning speed and powder flow rate influence on the properties of laser metal deposition of titanium alloy. Int. J. Adv. Manuf. Technol. 2017, 91, 2419-2426. [CrossRef]

24. Mahamood, R.M. Effect of Laser Power and Gas Flow Rate on Properties of Directed Energy Deposition of Titanium Alloy. Lasers Manuf. Mater. Process. 2018, 5, 42-52. [CrossRef]

25. Erinosho, M.F.; Akinlabi, E.T.; Pityana, S. Laser Metal Deposition of Ti6Al4V/Cu Composite: A Study of the Effect of Laser Power on the Evolving Properties. In Proceedings of the World Congress of Engineering (WCE), London, UK, 2-4 July 2014.

26. Heigel, J.C.; Michaleris, P.; Reutzel, E.W. Thermo-mechanical model development and validation of directed energy deposition additive manufacturing of Ti-6Al-4V. Addit. Manuf. 2015, 5, 9-19. [CrossRef]

27. Yan, M.; Yu, P. An Overview of Densification, Microstructure and Mechanical Property of Additively Manufactured Ti-6Al-4V — Comparison among Selective Laser Melting, Electron Beam Melting, Laser Metal Deposition and Selective Laser Sintering, and with Conventional Powder Metallurgy. In Sintering Techniques of Materials; Lakshmanan, A., Ed.; InTech: London, UK, 2015.

28. Li, P.H.; Guo, W.G.; Huang, W.D.; Su, Y.; Lin, X.; Yuan, K.B. Thermomechanical response of 3D laser-deposited Ti-6Al-4V alloy over a wide range of strain rates and temperatures. Mater. Sci. Eng. A 2015, 647, 34-42. [CrossRef]

29. Qiu, C.; Ravi, G.A.; Dance, C.; Ranson, A.; Dilworth, S.; Attallah, M.M. Fabrication of large Ti-6Al-4V structures by direct laser deposition. J. Alloys Compd. 2015, 629, 351-361. [CrossRef]

30. Carroll, B.E.; Palmer, T.A.; Beese, A.M. Anisotropic tensile behavior of Ti-6Al-4V components fabricated with directed energy deposition additive manufacturing. Acta Mater. 2015, 87, 309-320. [CrossRef]

31. Sterling, A. J.; Torries, B.; Shamsaei, N.; Thompson, S.M.; Seely, D.W. Fatigue behavior and failure mechanisms of direct laser deposited Ti-6Al-4V. Mater. Sci. Eng. A 2016, 655, 100-112. [CrossRef]

32. Paydas, H.; Mertens, A.; Carrus, R.; Lecomte-Beckers, J.; Tchuindjang, J.T. Laser cladding as repair technology for Ti-6Al-4V alloy: Influence of building strategy on microstructure and hardness. Mater. Des. 2015, 85, 497-510. [CrossRef]

33. Wang, T.; Zhu, Y.Y.; Zhang, S.Q.; Tang, H.B.; Wang, H.M. Grain morphology evolution behavior of titanium alloy components during laser melting deposition additive manufacturing. J. Alloys Compd. 2015, 632, 505-513. [CrossRef]

34. Nassar, A. R.; Keist, J.S.; Reutzel, E.W.; Spurgeon, T.J. Intra-layer closed-loop control of build plan during directed energy additive manufacturing of Ti-6Al-4V. Addit. Manuf. 2015, 6, 39-52. [CrossRef]

35. Raju, R.; Duraiselvam, M.; Petley, V.; Verma, S.; Rajendran, R. Microstructural and mechanical characterization of Ti6Al4V refurbished parts obtained by laser metal deposition. Mater. Sci. Eng. A 2015, 643, 64-71. [CrossRef]

36. Ravi, G.A.; Qiu, C.; Attallah, M.M. Microstructural control in a Ti-based alloy by changing laser processing mode and power during direct laser deposition. Mater. Lett. 2016, 179, 104-108. [CrossRef]

37. Yan, L.; Chen, X.; Li, W.; Newkirk, J.; Liou, F. Direct laser deposition of Ti-6Al-4V from elemental powder blends. Rapid Prototyp. J. 2016, 22, 810-816. [CrossRef]

38. Wolff, S.; Lee, T.; Faierson, E.; Ehmann, K.; Cao, J. Anisotropic properties of directed energy deposition (DED)-processed Ti-6Al-4V. J. Manuf. Process. 2016, 24, 397-405. [CrossRef] 
39. Zhai, Y.; Lados, D.A.; Brown, E.J.; Vigilante, G.N. Fatigue crack growth behavior and microstructural mechanisms in Ti-6Al-4V manufactured by laser engineered net shaping. Int. J. Fatigue 2016, 93, 51-63. [CrossRef]

40. Sridharan, N.; Chaudhary, A.; Nandwana, P.; Babu, S.S. Texture Evolution During Laser Direct Metal Deposition of Ti-6Al-4V. JOM 2016, 68, 772-777. [CrossRef]

41. Reichardt, A.; Dillon, R.P.; Borgonia, J.P.; Shapiro, A.A.; McEnerney, B.W.; Momose, T.; Hosemann, P. Development and characterization of Ti-6Al-4V to 304L stainless steel gradient components fabricated with laser deposition additive manufacturing. Mater. Des. 2016, 104, 404-413. [CrossRef]

42. Keist, J. S.; Palmer, T.A. Role of geometry on properties of additively manufactured Ti-6Al-4V structures fabricated using laser based directed energy deposition. Mater. Des. 2016, 106, 482-494. [CrossRef]

43. Marshall, G.J.; Young, W.J.; Thompson, S.M.; Shamsaei, N.; Daniewicz, S.R.; Shao, S. Understanding the Microstructure Formation of Ti-6Al-4V During Direct Laser Deposition via In-Situ Thermal Monitoring. JOM 2016, 68, 778-790. [CrossRef]

44. Ogunlana, M.O.; Akinlabi, E.T. Influence of process parameters on porosity behaviour of laser metal deposited titanium composites. In Proceedings of the World Congress on Engineering and Computer Science, San Francisco, CA, USA, 19-21 October 2016.

45. Zhong, C.; Chen, J.; Linnenbrink, S.; Gasser, A.; Sui, S.; Poprawe, R. A comparative study of Inconel 718 formed by High Deposition Rate Laser Metal Deposition with GA powder and PREP powder. Mater. Des. 2016, 107, 386-392. [CrossRef]

46. Ahsan, M.N.; Pinkerton, A.J.; Moat, R.J.; Shackleton, J. A comparative study of laser direct metal deposition characteristics using gas and plasma-atomized Ti-6Al-4V powders. Mater. Sci. Eng. A 2011, 528, 7648-7657. [CrossRef]

47. Mahamood, R.M.; Akinlabi, E.T. Corrosion behavior of laser additive manufactured titanium alloy. Int. J. Adv. Manuf. Technol. 2018, 99, 1545-1552. [CrossRef]

48. Han, Y.; Lu, W.; Jarvis, T.; Shurvinton, J.; Wu, X. Investigation on the Microstructure of Direct Laser Additive Manufactured Ti6Al4V Alloy. Mater. Res. 2015, 18, 24-28. [CrossRef]

49. Mahamood, R.M.; Akinlabi, E.T.; Shukla, M.; Pityana, S. Scanning velocity influence on microstructure, microhardness and wear resistance performance of laser deposited Ti6Al4V/TiC composite. Mater. Des. 2013, 50, 656-666. [CrossRef]

50. Pederson, R. Microstructure and Phase Transformation of Ti-6Al-4V. Ph.D. Thesis, Luleå Tekniska Universitet, Luleå, Sweden, 2002.

51. Banerjee, D.; Williams, J. C. Perspectives on titanium science and technology. Acta Mater. 2013, 61, 844-879. [CrossRef]

52. Ahmed, T; Rack, H.J. Phase transformationfs during cooling in $\alpha+\beta$ titanium alloys. Mater. Sci. Eng. A 1998, 243, 206-211. [CrossRef]

53. Liu, S.; Shin, Y.C. Additive manufacturing of Ti6Al4V alloy: A review. Mater. Des. 2019, 164, 107552. [CrossRef]

54. Zhang, S. Research on the Heat Treated Microstructures and Properties of Laser Solid Forming Ti-6Al-4V Alloy. Ph.D. Thesis, Northwestern Polytechnical University, Xi'an, China, 2009.

55. Sieniawski, J.; Ziaja, W.; Kubiak, K.; Motyka, M. Microstructure and mechanical properties of high strength two-phase titanium alloys. In Titanium Alloys-Advances in Properties Control; IntechOpen: London, UK, 2013.

56. Saboori, A.; Gallo, D.; Biamino, S.; Fino, P.; Lombardi, M. An Overview of Additive Manufacturing of Titanium Components by Directed Energy Deposition: Microstructure and Mechanical Properties. Appl. Sci. 2017, 7, 883. [CrossRef]

57. Lu, J.; Chang, L.; Wang, J.; Sang, L.; Wu, S.; Zhang, Y. In-situ investigation of the anisotropic mechanical properties of laser direct metal deposition Ti6Al4V alloy. Mater. Sci. Eng. A 2018, 712, 199-205. [CrossRef]

58. Grong, O. Metallurgical Modelling of Welding; Institute of Materials: London, UK, 1997.

59. Galarraga, H.; Warren, R.J.; Lados, D.A.; Dehoff, R.R.; Kirka, M.M.; Nandwana, P. Effects of heat treatments on microstructure and properties of Ti-6Al-4V ELI alloy fabricated by electron beam melting (EBM). Mater. Sci. Eng. A 2017, 685, 417-428. [CrossRef]

60. Ervin, J.K. Post Heat Treatment Effects of Ti-6Al-4V Produced via Solid Freeform Electron Beam Melting. Master thesis, North Carolina State University, Raleigh, North Carolina, USA, 2008. 
61. Shao, H.; Zhao, Y.; Ge, P.; Zeng, W. Influence of cooling rate and aging on the lamellar microstructure and fractography of TC21 titanium alloy. Metallogr. Microstruct. Anal. 2013, 2, 35-41. [CrossRef]

62. Meyer, L. W.; Krüger, L.; Sommer, K.; Halle, T.; Hockauf, M. Dynamic strength and failure behavior of titanium alloy Ti-6Al-4V for a variation of heat treatments. Mech. Time-Depend. Mater. 2008, 12, 237-247. [CrossRef]

(C) 2020 by the authors. Licensee MDPI, Basel, Switzerland. This article is an open access article distributed under the terms and conditions of the Creative Commons Attribution (CC BY) license (http:/ / creativecommons.org/licenses/by/4.0/). 